\title{
Outlying Museums of the Empire*
}

$\mathrm{T}$ $\mathrm{HE}$ great survey of the museums of the Empire, conceived by Sir Henry Miers and S. F. Markham, has now been completed by them with the assistance of Dr. F. A. Bather, T. Sheppard and others. The final reports, on the museums in scattered outliers of the British Empire, bring to a close a series of surveys which has reviewed more than a thousand museums and art galleries. For the accomplishment and success of these surveys, as well as to the surveyors, credit must be awarded to the Carnegie Corporation of New York which financed the inquiries, and to the Museums Association which acted as general headquarters and under the name of which the reports have been published. Along with the reports proper (bound in paper covers), there are issued (bound in eloth, as if for much service) a directory of the museums in Australia and New Zealand and another of those in the scattered islands of the Empire, compilations the merit of which makes it certain that from this starting. point the progress of these museums will be measured.

The condition of the isolated and island museums is the most unsatisfactory revealed by the Empire Survey. "The reason may be possibly historic, possibly psychological, but whatever the cause all observers agree that the islands of the British Empire present one of the most difficult problems in the realm of cultural services." Yet from the reports it is clear, and one's own knowledge of their publications confirms, that in places excellent scientific work has been done, as in the Raffles Museum at Singapore or the Sarawak Museum at Kuching. But in most places valuable scientific material is disappearing with little attempt at collection and conservation, simply because finances are inadequate. Exhibited collections suffer from the same inadequacies of money and staff, though the fact that in several

* Reports on the Museums of Ceylon, British Malaya, the West Indies, etc. Pp. 58. Directory of Museums in Ceylon, British Malaya, British Guiana. Pp. 67. (London: Museums Association, 1933-1934.) British Guiana. Pp. 67. (London: Museums Association, 1933-1934.)
Reports, with Directory, 5s. A Report on the Museums and Art Reports, with Directory, 5s. A Report on the Museums and Art
Galleries of Australia, by S. F. Markham and Prof. H. C. Richards, to the Carnegie Corporation of New York; and A Report on the to the Carnegie Corporation of New York; and A Report on the
Museums and Art Galleries of New Zealand, by S. F. Markham and Museums and Art Galleries of New Zealand, by S. F. Markham and
$\mathbf{W} . \mathbf{R}$. B. Oliver, to the Carnegie Corporation of New York. Pp. $\mathbf{v}+\mathbf{R} . \mathbf{B}+\mathbf{1 3}$ plates. Directory of Museums and Art Galleries in Australia and New Zealand. Compiled by S. F. Markham and Dr. 1934.) Richards. Pp. 115. (London: Museums Association, 1933- of the places illiterate natives form (as in Colombo) an overwhelming proportion of the museum visitors, must tend to discourage the utmost effort at arrangement, since neither English nor vernacular labels are understood. Yet these natives get pleasure and interest from the exhibits themselves.

Many of the remarks in the report on Australia and New Zealand apply to both countries, and indeed to other Dominions. Both have been severely hit by the depression and the staffs of their museums have not kept pace with their growth or have been actually reduced, with the inevitable deterioration. Over and over again it is insisted that the chief need of a museum is a competent and keen curator, who deserves an adequate salary. We read of one of the oldest and most important museums being run by a director and a taxidermist and of university-trained botanists and entomologists receiving less than $£ 3$ a week. Buildings are often inadequate and liable to destruction by fire. In these circumstances the good work already accomplished, generally by private or municipal effort (more marked in New Zealand than in Australia), is to be warmly commended.

Writing for the Carnegie Corporation, the authors naturally emphasise the exhibition and educational side of museum work and occasionally seem merely to tolerate the researches made known by the museums in many excellent publications. No doubt they themselves actually realise that in a new country being changed by civilisation the first duty of a museum is conservation and that research must precede exposition. Governing authorities, however, are slow to realise the help that museums might give to education, to general culture, and to the severely practical work of life.

The advantages of co-operation are insisted on, and here the Museums Association can extend its good work. Recently it has brought into being a strong Empire Committee, on which representatives of the Home Government and of the Dominions meet those who have conducted the surveys, in order to administer to best advantage the funds allotted by the Carnegie Corporation. But loans, exchanges, and the pooling of information are no less important. The Dominions desire much from the Homeland, but is it not ridiculous that type-specimens of British Jurassic plants and shells should, as the Directory tells us, be in an Antipodean museum ?

\section{The Roll-call of the Hydrogens (Hydranes) \\ By Prof. Henry E. Armstrong, F.r.s.}

1. THE task of naming the homologues of hydrogen is not to be undertaken lightly. Nomenclature is of such importance that all considerations should be laid aside, except those of reasoned ex. pediency and sound philological practice. The example set by Faraday, just a century ago, in framing names for use in describing and discussing electrochemical phenomena, may well serve us to-day. His words have stood the test of time, because of the extreme care with which they were chosen.

2. The new gases (from water) are clearly all Hydrogens (Water-stuffs), as each has its own water in water. They are to be grouped under their Atomic Number 1, as homologous members of the first term in the periodic series of elements. It would seem to be desirable to have an index name common to all members of the group. Deuterium is in no way reminiscent of water and also has no particular group significance. 'Second to what ?' is the question that at once arises. The name would be a fit one for the first member of the second group (Atomic Number 2) in the periodic series. If we could agree so to use it, succeeding groups might well have similarly significant group names-Triterium, Tetraterium, etc., up to 92 , in addition to the familiar names.

3. Members of the first group are logically all to be regarded and represented as Hydrogens, in the same way that members of the $\mathrm{C}_{n} \mathrm{H}_{2 n+2}$ series of saturated hydrocarbons are all included under the group name 